\title{
O CONTEXTO HISTÓRICO DAS POLÍTICAS PÚBLICAS DE LAZER NO BRASIL
}

\author{
Recebido em: 05/09/2010 \\ Aceito em: 17/12/2010 \\ Regimênia Maria Braga de Carvalho ${ }^{1}$ \\ Universidad Autónoma de Asunción \\ Asunción - Paraguai \\ Angelo Vargas $^{2}$ \\ Universidade Federal do Rio de Janeiro (UFRJ) \\ Rio de Janeiro - RJ - Brasil
}

RESUMO: Tratar o lazer como elemento essencial para o desenvolvimento social é algo que vem sendo defendido como uma ideia que expressa a garantia de direitos. Historicamente, o lazer compôs a rotina social dos indivíduos, tanto que os registros de tais fatos remontam à Idade Antiga. Porém, ressalta-se que ao longo da história, o lazer foi analogamente tratado como ócio. Com o advento da Revolução Industrial tornou-se mais evidente a relação com a produtividade na sociedade capitalista e a necessidade de descanso e tempo livre. A partir daí, a relevância do lazer como agente minimizador de acidentes de trabalho e desgastes de natureza profissional consolidou-se nos setores de produção públicos e privados. Nesse sentido, este artigo enfatiza o marco histórico do lazer no setor de produção industrial desde o século XIX até o presente. No Brasil o fortalecimento da construção de uma política para o lazer se dá através do SESC e do SESI.

PALAVRAS-CHAVE: Atividades de Lazer. História. Política. Indústrias. Descanso.

\section{THE HISTORICAL CONTEXT OF PUBLIC POLICY FOR LEISURE IN BRAZIL}

ABSTRACT: Treating leisure as an essential element for social development is something that has been seen as an idea which expresses the guarantee of human rights.

\footnotetext{
${ }^{1}$ Doutoranda em Ciência do Movimento Humano pela Universidad Autónoma de Asunción.

2 Professor da UFRJ, UNESA, Polícia Militar do Estado do Rio de Janeiro, LECSU (Laboratório de Estudos da Cultura Social Urbana).
} 
Historically, leisure composed the social routine of individuals, given that records of such events remote to ancient Rome and Greece. However, it is clear that leisure was historically understood in its essence as a characterization of idleness. With the Industrial Revolution, the relationship between productivity in a capitalist society and the need for rest and leisure time became more evident. Since then, leisure was established as a relevant agent for minimizing working accidents and other professional drawbacks in public and private sectors of production. Thus, this article emphasizes the historic milestone in leisure in the segment of industrial production since the $19^{\text {th }}$ century to the present. In Brazil, the strengthening of building a policy for leisure is brought up by the SESC and SESI.

KEYWORDS: Leisure Activities. History. Politics. Industry. Rest.

\section{Introdução: a linha histórica do lazer}

Este artigo foca a temática do lazer enquanto elemento sócio-histórico desde o seu surgimento no Ocidente como atividade de cunho recreativo até o momento atual, analisa de forma científica sua relação socioeconômica e cultural, corrobora a sua relevância no século XXI e discute a eminente necessidade de criação de uma política que abranja e resguarde os direitos do homem e conduza-o ao pleno exercício da sua cidadania.

No sentido etimológico do lazer, detectam-se três tendências: na primeira, o que caracteriza o lazer é a idéia de permissão para atuar. O lazer seria um conjunto de atividades nas quais predomina a ausência de restrições, de censuras, de proibições, de repressão; na segunda, seria a ausência de impedimentos de ordem temporal. O lazer seria, antes de tudo, um tempo livre, sem restrições, sem obrigações, sem compromissos. Já para a terceira tendência, seu sentido etimológico radicaria em uma qualidade de ordem subjetiva: o lazer seria constituído por uma série de atividades 
livremente escolhidas, atividades autônomas e agradáveis, benéficas física e psicologicamente Jimenez Guzman ${ }^{3}$ (1986, apud GOMES, 2004).

Entre os teóricos existem ainda debates sobre o surgimento do lazer. De um lado, estão aqueles cuja reflexão remonta à sociedade greco-romana. Por outro lado, aqueles que afirmam ser esta atividade uma consequência cultural das emancipações sociais dos séculos XIX e XX.

Para os primeiros, o lazer se origina na noção grega de scholé, tempo ocupado por atividades ideais e nobres para o ser, por atividades livres como a contemplação teórica, a especulação filosófica e o ócio. Numa segunda perspectiva, o sentido atual de lazer provém da noção romana de otium em contraposição a negotium. Na época republicana, os homens livres podiam exercer várias atividades, o comércio, o artesanato, o sacerdócio, a jurisprudência e a agricultura. O trabalho duro era para os escravos. Na época imperial eram muito poucos os cidadãos que trabalhavam. A plebe era sustentada pelo estado, que se sentia na necessidade de lhe preencher o tempo com espetáculo e outras distrações gratuitas. Além disso, não chega a ser coincidência o fato do termo lazer derivar do latim licere, ou seja, "ser lícito", "ser permitido" (Cf. Otium e negotium. Disponível em: www.exames.org/index.php?option=com_docman\&task... Acesso em: 20 jun 2010).

Werneck (2000) enfoca a ótica epistemológica do lazer quando associa o seu sentido à antiguidade clássica analisando os seus significados rega para traçar o início de uma linha histórica deste fenômeno. Nesse sentido, diversas atividades culturais

\footnotetext{
3 JIMENEZ GUZMAN, Luís Fernando. Teoria Turística. Bogotá: Universidade Autônoma de Colômbia, 1986.
} 
greco-romanas foram compreendidas, sendo estas, referenciais de entretenimento e lazer. Na Grécia, o lazer era caracterizado pelas competições olímpicas; peças teatrais; recitais poéticos; apresentações de dança e canto, dentre outras. Em Roma, por exemplo, tinham os combates de gladiadores; corrida de bigas; banquetes e festas; o pão e o circo.

Com o passar dos tempos o lazer se diferencia, pois as necessidades sociais impõem atividades distintas aos indivíduos, levando-se em conta as condições, valores, características culturais e organização dos grupos e localidades onde se situam. Cavalcanti (1981) afirma que o lazer tomou a dimensão de hoje após a Revolução Industrial, quando então a jornada de trabalho começou a diminuir paulatinamente, muito embora "os fundamentos históricos do Lazer sejam anteriores à sociedade industrial, porque sempre existiu o trabalho e o não-trabalho em qualquer sociedade". $([\mathrm{s} / \mathrm{p}])$.

As transformações decorrentes do processo da Revolução Industrial que levaram a uma rígida e nítida delimitação entre lazer e trabalho. Segundo Gomes (2003), essa delimitação da jornada de trabalho acabou distinguindo o tempo de trabalho do tempo de não trabalho, ou seja, separando o tempo de trabalho do tempo livre (dentro do qual o tempo de lazer estaria inserido). Embora não considere que o lazer tenha surgido nessa época, ainda assim a autora destaca a importância das transformações que ocorreram nesse período e que foram "decisivas para que o lazer, entre outras dimensões da vida, fosse revestido de características próprias, configurando-se da forma como conhecemos hoje" (GOMES, 2003, p. 61-62).

A contínua busca de formas de diversão não significa ter sempre existido o que hoje chamamos por lazer, na medida em que tais formas de diversão guardam especificidades condizentes com cada época, que devem ser analisadas com cuidado. 
Por certo, existem similaridades com o que foi vivido em momentos anteriores - e mesmo por isso devemos conhecê-los -, mas o que hoje entendemos como lazer guarda peculiaridades que somente podem ser compreendidas em sua existência concreta atual. (MELO, 2003).

A condição social após a Revolução Industrial possibilitou que o lazer fosse estendido às classes populares, tendo em vista que até então era privilégio de poucos. Mas tal fato relacionou-se à conquista trabalhista da carga horária máxima de trabalho diário e a importância do descanso. Desta forma, o reconhecimento do tempo livre entre os dias de trabalho e os dias de descanso fez do lazer uma atividade componente da manutenção da qualidade de vida das pessoas.

E, no atual momento histórico, o lazer não seria nada além do que um fenômeno carente de sentido filosófico, ostentatório e diferenciador de classes sociais. E mais: o lazer seria uma indústria a serviço do espetáculo e do entretenimento.

\section{O lazer no Brasil: o contexto da indústria e do comércio}

Segundo Amaral (2003), a década de 1940 significou para o Brasil um período de adaptação às recentes mudanças no cenário interno e externo: a renúncia de Getúlio Vargas, o fim da Segunda Guerra Mundial, a posse de Eurico Gaspar Dutra na Presidência da República e o crescimento da industrialização. Era uma época com perspectivas de liberdade e democracia. Por outro lado, aumentavam as tensões sociais - reflexo de problemas nos setores de alimentação, saúde, transportes e habitação.

Amaral (2003) assinala ainda que entre os empresários da indústria, da agricultura e do comércio estava clara a necessidade de criar um plano de ação social para o Brasil. O pensamento ganhou força após uma reunião de sindicatos patronais e 
empregados de Minas Gerais, onde foi elaborada e exposta a Carta Econômica de Teresópolis, de 1945. A partir dessa reunião, foi instituída a Carta da Paz Social, amparada pelos princípios de solidariedade social que norteariam a criação do SESI (Serviço Social da Indústria) em 01 de julho de 1946.

Sendo o $\mathrm{SESI}^{4}$ uma entidade de direito privado, mantida e administrada pela indústria, tem o objetivo de melhorar a qualidade de vida do industriário e seus dependentes, incluindo ainda em suas atividades a prestação de serviços em saúde, educação, lazer, cultura e responsabilidade social.

O Decreto-Lei $n^{\circ}$ 9.403, assinado por Gaspar Dutra em 1946, atribuiu à Confederação Nacional da Indústria (CNI) a criação, direção e organização do Serviço Social da Indústria (SESI). Para isso, foi decisiva a liderança dos empresários Roberto Simonsen, em São Paulo, e Euvaldo Lodi, no Rio de Janeiro, já que foram eles que despertaram o governo para a necessidade de promover a integração e a solidariedade entre patrões e empregados.

No Brasil, o lazer até meados da década 1950 era um fenômeno pouco enfatizado. Passou a ser disseminado como um fenômeno social relevante para a manutenção do bem estar a partir dos seus precursores Inezil Marinho (que em 1957 publicou Educação física, recreação e jogos), Ethel Bauzer Medeiros (elaborou o projeto de recreação no Aterro do Flamengo no Rio de Janeiro) e Arnaldo Süssekind (que redigiu o projeto que se transformaria na Consolidação das Leis do Trabalho, Ministro do Trabalho e Previdência Social no governo Castello Branco de abril de 1964 a dezembro de 1965, representante do governo brasileiro no Conselho de Administração da Organização Internacional do Trabalho (OIT), tendo sido eleito presidente da

\footnotetext{
${ }^{4}$ Disponível em <http://www.cni.org.br/portal/main.jsp?lumChannelId=A81818B146A9BCF01146AC2 3EDD2B39> Acesso em 23.03.2010.
} 
Comissão de Atividades Práticas, distribuiu um questionário sobre lazer entre o operariado e dirigiu o Serviço de Recreação Operária do Ministério do Trabalho). Este último é considerado um importante agente para a discussão do fenômeno em questão segundo a sua realidade na indústria. (DUMAZEDIER, 1978).

Além de Arnaldo Süssekind, na Bahia havia no final dos anos 1950 José Acácio Ferreira, autor do livro Lazer Operário, obra dividida em três partes: "Importância e significado do lazer"; "Lazer, industrialização e subdesenvolvimento" e "Lazer operário", com destaque final para a importância da participação mais ativa dos empregados nas atividades de lazer.

A definição clara no enfoque do texto para Ferreira surgiu a partir das 'palavras' de Gilberto Freyre em uma conferência realizada na Escola de Belas Artes da Bahia no ano anterior à publicação do livro. Freyre afirmou que à medida que a máquina substituía o homem, a organização do lazer tornava-se mais importante que a organização do trabalho (GOMES, 2003, p. 68).

No final dos anos 1960, o SESC realiza em São Paulo o "Seminário sobre o lazer: perspectivas para uma cidade que trabalha", com o propósito de discutir a temática do lazer no Brasil, junto aos estudiosos do assunto, tornando esta instituição precursora no País do levantamento da problemática em relação ao fenômeno e a realidade urbana relacionada ao trabalho (DUMAZEDIER, 1999).

Neste evento aconteceu a conferência de Renato Requixa que, em sua exposição, enfatizou a relevância do lazer no mundo contemporâneo, levantando a problemática relativa à validade do estudo do lazer nos países em desenvolvimento, investigando sua definição e características baseando-se na linha de pesquisa de Dumazedier. 
Com a intenção de discutir o assunto, Camargo (2001) representante da corrente "favorável", na linha de pesquisa de Dumazedier, vislumbrou a correlação do lazer com o contexto histórico brasileiro, por meio da apresentação de duas perspectivas distintas:

De um lado, a favor do tema, devem ser lembrados o SESC e alguns setores públicos minoritários, sobretudo de urbanistas, que não se conformavam com a degradação dos espaços urbanos e com a morte do centro histórico. Havia, também, os professores de educação física e os recreadores escolares, que se sentiam marginalizados em face da tônica dominante na escola. De outro, contrários, havia os empresários, os 'donos' do trabalho, em parceria inusitada com a sociologia estabelecida, sobretudo da USP e da PUC, sem deixar de mencionar a parcela majoritária dos assistentes sociais e outros profissionais que se dedicavam ao cuidado das populações carentes (CAMARGO, 2001, p. 145).

Analisando contextualmente o ponto de vista de Camargo sobre a exposição de Requixa no "Seminário sobre o lazer: perspectivas para uma cidade que trabalha", Werneck (2000, p. 96) afirmou que:

Tais divergências teóricas são contextualizadas por Camargo ao citar o pensamento de Requixa, para quem as sociedades urbanas apresentavam três estágios em relação à temática do lazer: num primeiro momento, negam a questão, através de diferentes argumentos; num segundo, o tema do lazer 'é percebido como importante face ao seu potencial terapêutico em relação a outras problemáticas urbanas, ou seja, dentro de um sentido instrumental'; e apenas num terceiro momento, 'percebe-se que o lazer é importante em si mesmo'. Estes estágios, do ponto de vista sociológico, refletem o processo de urbanização e industrialização de todas as sociedades capitalistas.

O SESI, tendo em vista a sua atuação como um referencial para o lazer da classe operária, além da sua eminente preocupação com o atendimento do operário brasileiro, e a sua estreita relação com o processo socio-histórico construído, merece destaque. 
Com a eminente preocupação de atendimento à classe operária, no final dos anos 1950, foi constituída no SESI a primeira equipe multidisciplinar composta por profissionais das áreas de serviço social, psicologia e pedagogos visando potencializar o atendimento aos operários.

Peter Drucker, nos anos 1970, em um de seus estudos sugeriu a substituição da visão conflitante dos tecnocratas entre Homem e Máquina pelas relações humanas a fim de que as empresas funcionassem também como um organismo social. O ponto-chave de sua defesa foi a ideia de que o mais importante em uma organização são as pessoas. A influência de seus pensamentos foi tão grande que ele frequentemente é chamado de Pai da Gestão. Essas suas idéias deram origem ao conceito de função social da empresa (DUMAZEDIER, 1980).

Naquela época, o desenvolvimento econômico do país exacerbava as diferenças sociais. Com as enormes perdas salariais e inúmeras greves que ocorriam nos grandes centros urbanos - o principal deles era São Paulo -, o SESI trouxe para o centro dos debates a preocupação do desenvolvimento de uma política direcionada ao lazer dos operários objetivando minimizar as insatisfações entre o empresariado e a classe trabalhadora.

\section{Refletindo as políticas públicas voltadas para o lazer e qualidade de vida}

Quando nos referimos ao lazer e ao esporte, apesar da constatação de que tais políticas foram estabelecidas em distintos períodos da história, mas foi após a Constituição da República Federativa do Brasil de 1988 que estas áreas foram compreendidas como direitos sociais no País. Diz o seu Art. $6^{\circ}$ que "são direitos sociais a educação, a saúde, a alimentação, o trabalho, a moradia, o lazer...”. No seu Art. $7^{\circ}$, 
inciso IV, decreta que o salário mínimo deve atender às "necessidades vitais básicas" do trabalhador e de sua família, inclusive o lazer. O Art. 217 , em seu $\S 3^{\circ}$, afirma que "o Poder Público incentivará o lazer, como forma de promoção social.” No Art. 227, lê-se que "é dever da família, da sociedade e do Estado assegurar à criança e ao adolescente, com absoluta prioridade, o direito à vida, à saúde, à alimentação, à educação, ao lazer..."

Conforme afirmou Carvalho (2002), as políticas públicas são construções participativas de uma coletividade, que visam a garantia dos direitos sociais dos cidadãos que compõem uma sociedade.

As relações do homem com o trabalho se transformaram ao longo do tempo, de acordo com as interferências das instituições sociais e determinaram os processos familiares, educacionais, religiosos e político-econômicos. Estes aspectos vão além das formas de organização do Estado e respaldam a efetivação do cumprimento dos direitos humanos.

Conforme Linhales (2001), nas administrações públicas, o esporte encontra-se diluído em setores sociais que o instrumentalizam para os mais variados fins, como, por exemplo, atividades meio ou complementar em políticas educacionais e de saúde. Porém, há que se ressaltar a importância do esporte como um bem cultural, historicamente construído pela humanidade e, portanto, passível de ser legitimado como um direito de todos.

As políticas públicas aparecem nesse contexto como uma possibilidade de atender as necessidades dos grupos sociais por ser necessária uma sistematização e planejamento de ações, visto que o desenvolvimento social não está simplesmente atrelado ao desenvolvimento econômico de maneira linear. 
Seguindo ainda com Carvalho (2002), muitos problemas enfrentados na gestão das políticas públicas advêm da escassez de recursos disponíveis para o atendimento social. No Brasil, a discussão sobre a proteção dos direitos humanos vem crescendo a cada dia através da realização de fóruns, da determinação de marcos legais, da organização civil em busca do comprometimento do setor público no sentido de melhorar as condições de pobreza e dignidade humana, desenvolvendo a cidadania e com isso aprofunda-se também a reflexão sobre a relevância do lazer para o trabalhador.

Numa perspectiva governamental democrática, o orçamento público vem a constituir um instrumento de extrema importância no sentido de monitorar as políticas públicas. E isso significa participar da discussão na elaboração de tais políticas, fiscalizar a execução e elaborar distintamente análises sobre suas implementações. $\mathrm{O}$ seu acompanhamento deve ser feito de forma participativa, constituindo uma maneira de pressionar o poder público para agir na busca da promoção da qualidade de vida da população.

As políticas públicas de lazer vêm crescendo nas reivindicações da sociedade pela busca de melhor qualidade de vida. A democratização dos planejamentos municipais torna a gestão mais flexível, fazendo com que os projetos sociais sejam elaborados centrados na realidade das comunidades.

Alguns conceitos de esporte e lazer embasam a prática de comunidades populares com vistas a tornar acessíveis atividades de recreação e ocupação do tempo livre. Além disso, a adaptação esportiva à cultura dos praticantes leva estas atividades a serem vivenciadas nos espaços sociais em momentos de descanso e descontração também no ambiente de trabalho. Desta maneira, o lazer relacionado ao esporte possibilita ao trabalhador o descanso necessário das suas atividades laborais. 
A utilização do tempo livre pelos indivíduos, potencializando o bem-estar em lugar do culto ao ócio, vem favorecer a integração desses indivíduos no ambiente de trabalho de maneira salutar. O lazer se manifesta diante de uma multiplicidade de trabalho individual e coletivo. Exige condições mínimas de realização, pois não é apreendido apenas sob a ótica da teoria.

Marcellino (2001) considera que, muito embora as pesquisas realizadas na área das atividades desenvolvidas no tempo livre enfatizem a atração exercida pelo tipo de equipamento construído, deve-se considerar que, para a efetivação das características do lazer é necessário, antes de tudo, que o tempo disponível corresponda um espaço disponível.

Nesse sentido, é relevante exaltar que o lazer atravessou por momentos históricos diversos, entrou na era pós-moderna sob novos olhares e críticas. Ele foi relacionado à condição de melhores índices de produção e do aumento da capacidade social em conviver com suas limitações devido à sobrecarga de trabalho $\mathrm{e}$ impossibilidades do pleno exercício da cidadania capaz de garantir a todos a qualidade de vida e espaços recreativos.

A mobilização deste tema na indústria trouxe à tona a emergente necessidade de redimensionar o conceito até então tratado conjuntamente com o tempo livre. Tornase necessário a transmutação de um modelo político social que introduz a idéia de potencializar o tempo livre do trabalhador no sentido de valorizar os espaços destinados a esses indivíduos para a prática do lazer.

\section{Considerações finais: lazer e ócio criativo}


O lazer no seu contexto histórico vem sendo modificado de acordo com as transformações socioeconômicas e culturais da sociedade global. Adstrito de cada época, desde a civilização greco-romana, esta atividade se apresentou com características peculiares às condições e necessidades de dado grupo social.

Com o decorrer dos séculos, no ocidente, o lazer é relacionado ao nível de produtividade dos trabalhadores tornando-se elemento indissociável da utilização do tempo livre de maneira a proporcionar melhores referenciais de produção. Este fato caracterizou-se fortemente com o advento da Revolução Industrial e solidificou-se após a Segunda Guerra Mundial.

As discussões sobre o tema foram aprofundadas quando o lazer passou a ser também relacionado como um direito social do trabalhador economicamente ativo. Dessa forma é que o empregador assume fundamental papel no sentido de difundir nas empresas e indústrias não só a reflexão, mas também a implementação de programas interventivos de lazer como elemento essencial para a melhoria da qualidade de vida.

A partir desse eixo histórico é que o lazer, já no século XX, passa a ser discutido no contexto dos seus aspectos sociais, como fator preponderante de garantia da manutenção do bem-estar cognitivo, afetivo e motor daqueles que se ocupam de tarefas intensas por longos períodos consecutivos em sua jornada de trabalho.

Hodiernamente, torna-se incontestável a valia do lazer nos espaços laborais, tanto para propiciar o descanso, como para utilização do tempo livre de forma a aproximar os indivíduos da sua família e criar vínculos de amizade, o que contribuiria diretamente com a melhoria da sua condição psicossocial. A abordagem do tema em questão é fundamental para abrir espaços e criar instrumentos para o aprofundamento da 
reflexão sobre o teor histórico do lazer e sua relação com a construção de uma política nacional capaz de garantir como direito humano a expressão e vivência deste fenômeno. No século XXI, trabalho e lazer passam a ser indissociáveis. Não deixa de ser interessante ressaltar a existência de uma indústria do lazer, isto é, uma indústria onde o ócio é um bom negócio. Trigo (2003) afirma que as pessoas estão alienadas por estarem excluídas do processo cultural-educacional e tudo virou espetáculo: a política, a religião, a mídia, e, é claro, o lazer como indústria de entretenimento. "Voltamos à questão da cidadania: quanto mais as pessoas tiverem acesso à educação, mais reflexão crítica nós teremos, e menos as pessoas ficarão à mercê desse cenário: só espetáculo", declara o estudioso.

Nesse sentido, caberia citar a lição do sociólogo do trabalho italiano Masi (2000), que define "ócio crativo" através da interrelação entre três elementos: trabalho, estudo e jogo. Trabalho envolve economicamente as funções necessárias ao cumprimento de uma tarefa. O estudo é a possibilidade se obter conhecimento através do trabalho constante, utilizando os recursos que a sociedade digital proporciona, como o uso da internet, por exemplo. Jogo, por seu lado, é o espaço lúdico de lazer, brincadeira e convivência que deve estar presente em qualquer atividade que se faça. Seria a forma de evitar a mecanização do trabalho, o adestramento do estudo e a automatização do jogo.

Mas um fato é transparente e conclusivo: o espaço lúdico, autônomo e vital do lazer deve ser um direito inalienável e inegociável do cidadão brasileiro. 


\section{REFERÊNCIAS}

AMARAL, S. C. F. Políticas Públicas de Lazer e Participação Cidadã: entendendo o caso de Porto Alegre - Tese (Doutorado) - Educação Física - Universidade Estadual de Campinas: 2003.

CAMARGO, Luiz Otávio de Lima. Sociologia do lazer. Turismo como aprender, como ensinar. v. 2. São Paulo: Senac, 2001.

CARVAlHO, D. M. de. Saúde e Democracia (Editorial). In: Cadernos de Saúde Coletiva. Universidade Federal do Rio de Janeiro. Núcleo de Estudos de Saúde Coletiva. Rio de Janeiro, 2002.

CAVALCANTI, Kátia Brandão. A função cultural do esporte e suas ambiguidades sociais. In: COSTA, Lamartine Pereira da (Org). Teoria e prática do esporte comunitário e de massa. Rio de Janeiro: 1981, p. 301-316.

CONSTITUIÇÃO DO BRASIL. Disponível em: http://www.planalto.gov.br/ccivil_03/constituicao/constitui\%C3\%A7ao.htm. Acesso em: 08 jul 2010.

DUMAZEDIER, Joffre. Sociologia empírica do lazer. São Paulo: Perspectiva, 1999.

. Valores e Conteúdos Culturais do Lazer. Série Lazer. São Paulo: Biblioteca Científica SESC, 1980.

Teoria sociológica da decisão. São Paulo: Sesc/Celazer, 1978.

GOMES, C. L. Significados de recreação e lazer no Brasil: reflexões a partir da análise de experiências institucionais (1926-1964). Tese (Doutorado) - Educação Universidade Federal de Minas Gerais, 2003.

GOMES, Cristina Marques. Pesquisa Científica em Lazer no Brasil - Bases Documentais e Teóricas. Dissertação (Mestrado) - São Paulo: ECA / USP 2004.

JIMENEZ GUZMAN, Luís Fernando. Teoria Turística. Bogotá: Universidade Autônoma de Colômbia, 1986.

LinhaleS, M. A. Jogos da Política, Jogos do Esporte. In: MARCELlinO, N. C. (Org.). Lazer e esporte: políticas públicas. Campinas: Autores Associados, 2001.

MARCELLINO, N. C. (Org.). Lazer e esporte: políticas públicas. Campinas: Autores Associados, 2001.

MASI, Domenico de. O ócio criativo. Rio de Janeiro: Sextante, 2000.

MELO, V. A. Lazer e camadas populares: reflexões a partir da obra de Edward Palmer Thompson. Revista Movimento, Porto Alegre, v. 7, n. 14, pp. 4-19, 2003. 
OTIUM E NEGOTIUM. Disponível em:

www.exames.org/index.php?option=com_docman\&task... Acesso em: 20 jun.2010.

SÜSSEKIND, Arnaldo. Homenagem a Arnaldo Süssekind é um dos pontos altos do $8^{\circ}$ Congresso. Disponível em: http://www.jusbrasil.com.br/noticias/173541/homenagem-aarnaldo-sussekind-e-um-dos-pontos-altos-do-8-congresso . Acesso em: 08 jul. 2010.

TRIGO, Luiz Gonzaga Godoi. Entretenimento - uma crítica aberta. São Paulo: Senac, 2003.

WERNECK, C. L. G. Lazer, trabalho e educação: relações históricas, questões contemporâneas. Belo Horizonte: Editora UFMG/Celar, 2000.

\section{Endereço dos Autores:}

Regimênia Maria Braga de Carvalho Universidade Autônoma de Assunción - Paraguai (UAA)

Rua Antonio José Santiago, 115 BL-B APTO 402 - Santa Barbara II

Dinamérica - Campina Grande - 58100-000

Endereço Eletrônico: regimenia_cg@yahoo.com.br 